\title{
Boundary layer structure and decoupling from synoptic scale flow during NAMBLEX
}

\author{
E. G. Norton ${ }^{1}$, G. Vaughan ${ }^{1}$, J. Methven ${ }^{2}$, H. Coe ${ }^{1}$, B. Brooks ${ }^{3}$, M. Gallagher ${ }^{1}$, and I. Longley ${ }^{1}$ \\ ${ }^{1}$ School of Earth, Atmospheric and Environmental science, University of Manchester, Building Sackville Street, Manchester, \\ M60 1QD, UK \\ ${ }^{2}$ Department of Meteorology, University of Reading, P.O. Box 243, Earley Gate, Reading, RG6 6BB, UK \\ ${ }^{3}$ School of the Environment, University of Leeds, Leeds, LSJ 9JT, UK
}

Received: 21 March 2005 - Published in Atmos. Chem. Phys. Discuss.: 23 May 2005

Revised: 2 November 2005 - Accepted: 2 November 2005 - Published: 8 February 2006

\begin{abstract}
This paper presents an overview of the meteorology and planetary boundary layer structure observed during the NAMBLEX field campaign to aid interpretation of the chemical and aerosol measurements. The campaign has been separated into five periods corresponding to the prevailing synoptic condition. Comparisons between meteorological measurements (UHF wind profiler, Doppler sodar, sonic aneometers mounted on a tower at varying heights and a standard anemometer) and the ECMWF analysis at $10 \mathrm{~m}$ and $1100 \mathrm{~m}$ identified days when the internal boundary layer was decoupled from the synoptic flow aloft. Generally the agreement was remarkably good apart from during period one and on a few days during period four when the diurnal swing in wind direction implies a sea/land breeze circulation near the surface. During these periods the origin of air sampled at Mace Head would not be accurately represented by back trajectories following the winds resolved in ECMWF analyses. The wind profiler observations give a detailed record of boundary layer structure including an indication of its depth, average wind speed and direction. Turbulence statistics have been used to assess the height to which the developing internal boundary layer, caused by the increased surface drag at the coast, reaches the sampling location under a wide range of marine conditions. Sampling conducted below $10 \mathrm{~m}$ will be impacted by emission sources at the shoreline in all wind directions and tidal conditions, whereas sampling above $15 \mathrm{~m}$ is unlikely to be affected in any of the wind directions and tidal heights sampled during the experiment.
\end{abstract}

Correspondence to: E. G. Norton

(egn@aber.ac.uk)

\section{Introduction}

The North Atlantic Marine Boundary Layer EXperiment (NAMBLEX) took place during between 1 August and 1 September 2002 at the Mace Head atmospheric research station $\left(53.32^{\circ} \mathrm{N}, 9.90^{\circ} \mathrm{W}\right)$ on the west coast of Ireland (Heard, 2005).

Boundary layer depth and the strength of turbulent mixing are important considerations if measurements near the ground at Mace Head are to be related to long range transport and the influence of distant surface emissions or air entrained into the boundary layer from the free troposphere. Also it is important, especially for short-lived constituents, to know if an internal boundary layer develops during periods of onshore flow which partially shelters the site from marine boundary layer air off the open ocean. The main aims of NAMBLEX were to study oxidation chemistry, including that of halogens, in the marine boundary layer. As described elsewhere in this special issue, a range of chemical and aerosol measurements were made at Mace Head, and on aircraft flights in the vicinity of the site (Heard, 2005). In addition, several meteorological instruments were deployed during the campaign, including sonic anemometers mounted on a tower at heights between 7 and $24 \mathrm{~m}$, a standard anemometer at $21 \mathrm{~m}$, a UHF (1290 MHz) wind profiler and a Doppler sodar. In this paper we present a synthesis of the surface measurements with the UHF radar and large-scale synoptic fields, so that the chemical and aerosol measurements can be placed in a meteorological context. Of particular interest to the aims of this paper are to highlight periods when the local winds were decoupled from the synoptic flow. In such conditions trajectory calculations used to deduce air mass origins are unreliable, so the interpretation of the chemical measurements must proceed with caution.

(C) 2006 Author(s). This work is licensed under a Creative Commons License. 
Table 1. Characteristics of the UFAM mobile $1290 \mathrm{MHz}$ wind profiler.

\begin{tabular}{lc}
\hline Parameter & Value \\
\hline Transmitter Frequency & $1290 \mathrm{MHz}$ \\
Transmitter Wavelength & $23.2 \mathrm{cms}^{-1}$ \\
Transmitter Bandwidth & $10 \mathrm{MHz}$ \\
Beam Width & $8.5^{\circ}$ \\
Peak Power & $3500 \mathrm{~W}$ \\
Aperture & $4 \mathrm{~m}^{2}$ \\
Antenna Gain & $25 \mathrm{~dB}$ \\
Average Power & \\
"low mode" & $40 \mathrm{~W}$ \\
"high mode" & $100 \mathrm{~W}$ \\
Duty Cycle & \\
"low mode" & $1 \%$ \\
"high mode" & $2.5 \%$ \\
Spatial Resolution & \\
500 ns pulse & $75 \mathrm{~m}$ \\
1000 ns pulse & $150 \mathrm{~m}$ \\
1500 ns pulse & $375 \mathrm{~m}$ \\
Intrinsic Accuracy & \\
Speed & $<1 \mathrm{~ms}{ }^{-1}$ \\
Direction & $<10^{\circ}$ \\
\hline
\end{tabular}

This paper will first describe the specialist meteorological instrumentation used at Mace Head. We then present an overall meteorological summary of the NAMBLEX campaign, dividing it into five broad periods of similar synoptic type. Within each period, we present a time series of measurements from the various instruments and compare them to ECMWF analysis fields, to determine how well the analyses represented the local conditions. This in turn is a measure of the reliability of trajectory calculations based on ECMWF data. Subsequently, we concentrate on measurements of boundary-layer structure made by the UHF wind profiler, which show how representative the surface measurements were of the boundary layer as a whole. Finally turbulence statistics from the sonic anemometers are presented to asses the development of an internal layer.

\section{Instrumentation}

\subsection{UHF wind profiler}

"Clear-air" radars detect small scale irregularities in backscattered signals due to refractive index inhomogeneities caused by turbulence $C_{n}^{2}$; (Doviak and Zrnic, 1993). In the lower troposphere such inhomogeneities are mainly produced by humidity fluctuations. "Clear-air" Doppler shifts provide a direct measurement of the mean radial velocity along the radar beam. UHF radars also observe strong echoes from precipitation which can be distinguished from the "clear-air" echo by their intensity and spectral width.

The University Facility for Atmospheric Measurements (UFAM) mobile wind profiler is a "clear-air" UHF Doppler radar system designed by Degreane Horizon to measure three components of wind $24 \mathrm{~h}$ a day under all weather conditions. The radar operates at $1290 \mathrm{MHz}(23 \mathrm{~cm})$ with a peak power of $3.5 \mathrm{~kW}$ and beam width of $8.5^{\circ}$. The radar consists of three panels that emit and receive three separate beams, each panel being an array of 64 dipole antennas. The vertical beam measures the vertical component of the wind and the two beams at an elevation of $73^{\circ}$ and orthogonal azimuths sample radial velocities that have contributions from both vertical and horizontal wind components, to enable full wind vectors to be calculated. The radar provides measurements of wind speed and direction to an intrinsic accuracy of $<1 \mathrm{~ms}^{-1}$ and $<10^{\circ}$, respectively, according to the manufacturer's estimates.

The radar was cycled between measurements in two modes: the "low mode" with a Gaussian shaped pulse of length $500 \mathrm{~ns}$, inter-pulse period of $50 \mu \mathrm{s}$, average power of $40 \mathrm{~W}$ and duty cycle of $1 \%$; and the "high mode" with a rectangularly shaped pulse of length $1000 \mathrm{~ns}$, inter-pulse period of $40 \mu \mathrm{s}$, average power of $100 \mathrm{~W}$ and duty cycle of $2.5 \%$. The vertical resolution was $75 \mathrm{~m}$ for the "low mode" and $150 \mathrm{~m}$ for the "high mode" up to altitudes of approximately $1500 \mathrm{~m}$ and $4000 \mathrm{~m}$, respectively, depending on atmospheric conditions. The minimum altitude was $75 \mathrm{~m}$, although in practice it was found to be in the region of $200 \mathrm{~m}$ due to ground clutter echoes. The characteristics of the UFAM mobile wind profiler are summarized in Table 1.

Echoes from the three beams at each altitude were combined and both temporal and vertical windowing was used to distinguish the "clear-air" signal from any ground clutter or other interference. The wind profiler was located outside the top cottage $30 \mathrm{~m}$ above sea level and approximately $300 \mathrm{~m}$ from the shoreline. Measurements were derived every $15 \mathrm{~min}$ using consensus averaging over $30 \mathrm{~min}$ around the nominal observation time. The radar was operational $24 \mathrm{~h}$ a day under all weather conditions for the duration of the campaign apart from when a timing fault on the transmit-receive switch caused the limiter to fail. This resulted in no wind profiler data between the 15 and 21 August.

\subsection{Surface layer flux measurements}

Four 3-axis sonic anemometers (R. M. Young Model 81000) were mounted on $2 \mathrm{~m}$ long booms at 7, 10, 15 and $24 \mathrm{~m}$ above the surface on the south-western corner of an open scaffold tower of footprint $1 \times 2 \mathrm{~m}$. The ground on which the tower stood was around $7 \mathrm{~m}$ above the sea surface at midtide heights and was approximately $50 \mathrm{~m}$ from the shoreline. The ground fell away close to the tower and a mixed rocky foreshore extended to the ocean. In the easterly direction, the surface, composed mostly of rough grass and boulders, rose steadily over a distance of approximately $200 \mathrm{~m}$. The wind 
Table 2. Scintec MFas64 technical specifications.

\begin{tabular}{lc}
\hline Number of Elements & 64 \\
\hline Frequency Range & $1650-2750 \mathrm{~Hz}$ \\
Beam Angles & $0^{\circ}, \pm 22^{\circ}, \pm 29^{\circ}$ \\
Number of frequencies & Up to $80,(10$ within \\
& a single sequence $)$ \\
Number of vertical layers & 100 \\
Thickness of layer & $10-250 \mathrm{~m}$ \\
Maximum range & $1000 \mathrm{~m}$ \\
Minimum measurement height & $20 \mathrm{~m}$ \\
Intrinsic Accuracy & \\
Horizontal speed & $0.1-0.3 \mathrm{~ms}-1$ \\
Vertical speed & $0.03-0.1 \mathrm{~ms}^{-1}$ \\
Direction & $2-3^{\circ}$ \\
Averaging time & $1 \mathrm{~min}$ to $60 \mathrm{~min}$ \\
\hline
\end{tabular}

speeds in the $\mathrm{u}, \mathrm{v}$ and $\mathrm{w}$ co-ordinates were recorded every $0.05 \mathrm{~s}$, providing $10 \mathrm{~Hz}$ response and turbulence statistics as a function of height above the surface.

\subsection{Sodar}

The UFAM Doppler Sodar (SOnic Detection And Ranging) used during NAMBLEX was a Scintec MFAS64: a monostatic phased array system with 64 transmit and 64 receive transducers generating acoustic signals in the frequency range 1650 to $2750 \mathrm{~Hz}$. The phased array allows for both the transmitted and the received signals to be steered and the effect of side lobe interference reduced. Table 2 gives the detailed technical specifications of the system.

In a monostatic sodar system only the backscattered signal is detected. The intensity of the returned energy is proportional to the $\mathrm{C}_{T}^{2}$ function, which, in turn, is related to the thermal structure and stability of the atmosphere. $\mathrm{C}_{T}^{2}$ has characteristic patterns during ground-based radiation inversions, within elevated inversion layers, at the periphery of convective columns or thermals, in sea breeze/land breeze frontal boundaries, and at any interface between air masses of different temperatures. The acoustic scattering is determined by Bragg scattering laws and only inhomogenities of the order of $1 / 2$ the acoustic wavelength $(5-10 \mathrm{~cm})$ contribute. Using Doppler methods a measure of air movement at the position of the scattering eddy can be determined.

In this application ten frequencies were used (Table 3 ) with longer pulse lengths at the lower frequencies to increase measurement range and shorter pulses at higher frequencies to increase height resolution. The acoustic beam was steered around four reference directions in turn $(\mathrm{N}, \mathrm{E}, \mathrm{S}, \mathrm{W})$ with a pulse sequence as described in Table 3; alternate pulses were directed either side of the reference direction. The reason for the two low frequency short duration pulses at the end is so they don't interfere with the rest of the sequence.
Table 3. Pulse sequence used during NAMBLEX.

\begin{tabular}{cc}
\hline Frequency $(\mathrm{Hz})$ & Pulse length $(\mathrm{m})$ \\
\hline 2022.0 & 210 \\
2124.8 & 150 \\
2227.6 & 100 \\
2330.4 & 80 \\
2433.2 & 50 \\
2536.1 & 40 \\
2638.9 & 30 \\
2741.7 & 20 \\
1919.2 & 10 \\
1713.6 & 10 \\
\hline
\end{tabular}

The same pulse sequence was repeated 10 times for a given reference direction and the data averaged over $10 \mathrm{~min}$. Due to the proximity of housing to the research site the operation of the sodar was restricted to the hours of 09:00 to 17:00 local time. During rain events the sodar output was reduced to zero due to scattering of the acoustic signal off the falling rain droplets.

\section{Meteorological summary}

This meteorological summary for the NAMBLEX period has been compiled from synoptic charts published by Weather for 12:00 GMT and the European Meteorological Bulletin for 00:00 GMT, along with meteorological measurements made at Mace Head. The daily maximum temperature over the campaign period remained in the range $12-17^{\circ} \mathrm{C}$ except for a warm spell between 1 and 6 August when the temperature was $16-20^{\circ} \mathrm{C}$, with a warm spike on the 2 August (up to $24^{\circ} \mathrm{C}$ ). Prevailing synoptic conditions were used to separate the campaign into five periods:

1. 1 August to 5 August was complex, with the Azores high extending over the Atlantic and a stagnant low pressure system over Ireland and the UK, with recirculating fronts. Winds were very weak north-easterly from 1 to 5 August.

2. The Azores high extended towards Ireland and therefore winds were generally westerly or north-westerly from 6 to 11 August, apart from the 8th when the centre of a depression crossed just south of Mace Head.

3. From 12 to 17 August the Azores high retreated south allowing a succession of depressions to cross Ireland from the west.

4. On 18 August the air stagnated as the pressure gradually built. Anti-cyclonic conditions prevailed between 19 and 27 August. 

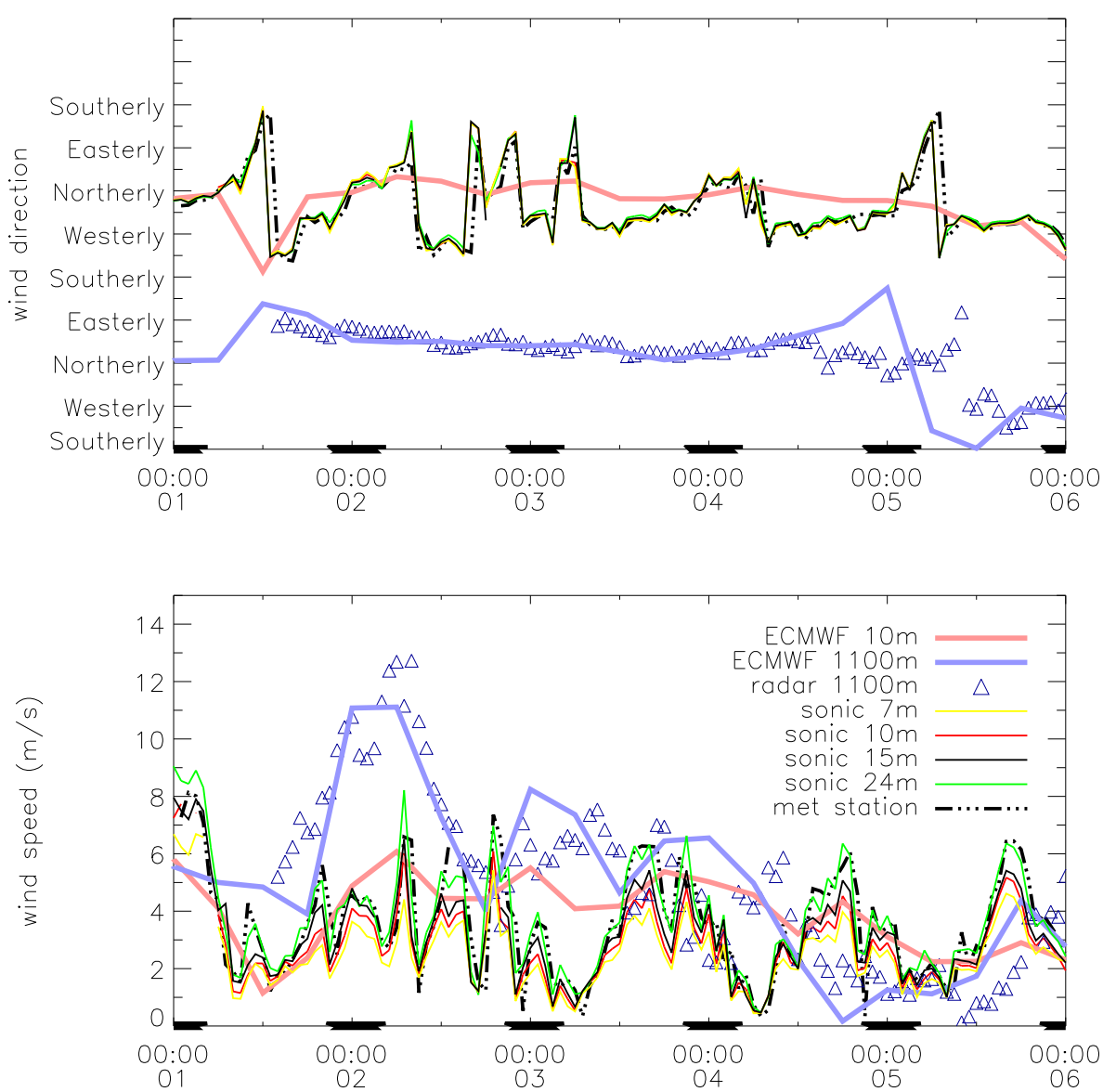

Fig. 1. Comparisons for period one between the ECMWF model analysis every $6 \mathrm{~h}$ at $10 \mathrm{~m}$ (pink line) and $1100 \mathrm{~m}$ (blue line) with measurements by sonic anemometers at $7 \mathrm{~m}$ (yellow line), $10 \mathrm{~m}$ (red line), $15 \mathrm{~m}$ (black line) and $24 \mathrm{~m}$ (green line), standard surface anemometer (black dashed line) and UHF wind profiler data (blue triangles) for (a) wind direction and (b) wind speed. The bold black line on the time axis indicates hours of darkness. On this plot for period one the lower and upper levels have been offset from one another for clarity. Note the close agreement in wind directions measured by the different anemometer make it is often difficult to distinguish between them.

5. The 28 to 31 August saw a return to westerlies and unsettled weather.

\section{Comparison between wind speed and direction mea- surements and meteorological analysis.}

In order to interpret the chemical measurements at Mace Head it is necessary to separate local and long-range contributions to the air sampled. This will be done by comparing the local wind measurements to those in the corresponding ECMWF analyses, and examining the consistency between surface winds and the flow aloft. The ECMWF analysis data used has a horizontal resolution T159 (grid spacing of about 1.125 degrees) and 60 levels in the vertical in terrain following eta-coordinates. The lowest level is at approximately $10 \mathrm{~m}$ and the 11 th is at about $1100 \mathrm{~m}$. We present comparisons of wind speed and direction for two altitude regions: at low level between the $7 \mathrm{~m}, 10 \mathrm{~m}, 15 \mathrm{~m}$ and $24 \mathrm{~m}$ sonic anemometers, a standard anemometer at $21 \mathrm{~m}$ and ECMWF analyses at $10 \mathrm{~m}$; and near the top of the boundary layer between the wind profiler at $1100 \mathrm{~m}$ and ECMWF analyses at $1100 \mathrm{~m}$. Sodar data at $100 \mathrm{~m}$ was also included in the comparisons for periods four and five. In the plots that follow night-time is indicated as the bold black line on the time axis.

\subsection{Meteorological period one}

Period one was the most complex meteorologically: local circulation effects dominated and a decoupled lower and upper boundary layer were observed. This is evident in the comparison between 1 and 6 August of the wind direction versus time (Fig. 1). The $1100 \mathrm{~m}$ winds from the radar (blue triangles) were from the north-eastern quadrant and agree with the ECMWF data (blue line) up to the afternoon of the 4th. A sharp veer of $90^{\circ}$ in wind direction observed by the radar around $12 \mathrm{~h}$ on the 5 th was seen in the model as well but $12 \mathrm{~h}$ earlier. Since this was a period of very low wind speed $\left(<2 \mathrm{~m} \mathrm{~s}^{-1}\right)$, the discrepancy between the two curves is much less significant than it appears. 

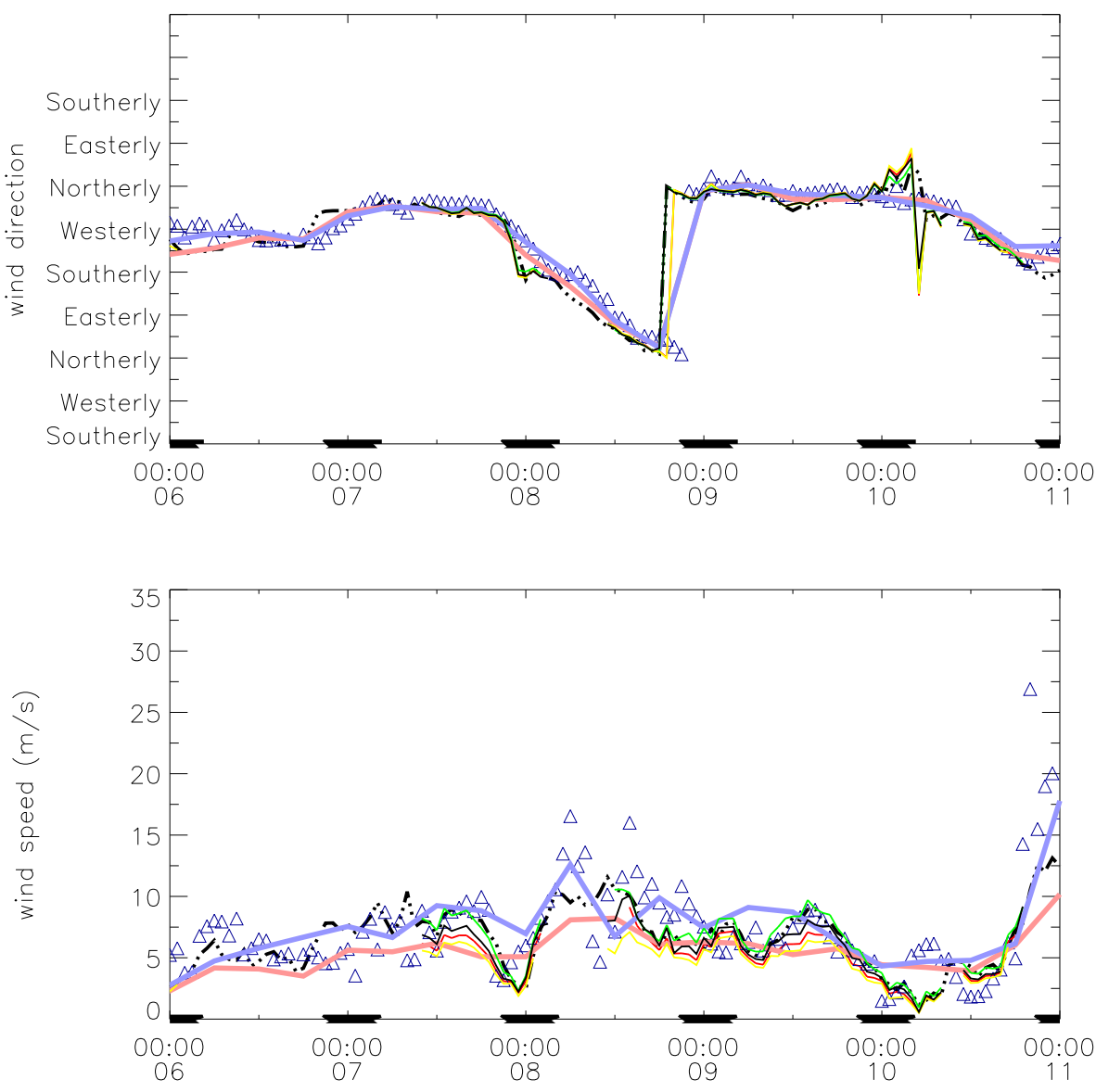

Fig. 2. The same as Fig. 1 but for period two.

The lower level winds were much more variable with a general tendency to be from the north-western quadrant. This variability was not represented in the ECMWF model winds which were generally northerly. During land breeze events the lower winds were measured to be more easterly. This is clear on the night of the 2nd, 4th and 5th when the wind direction switched to be more easterly than the model during the night. The opposite occurred a few hours after dawn when the direction shifted more westerly than the ECMWF model. This is a characteristic sea breeze pattern. Close agreement in the wind directions was observed between the sonics positioned at different heights on the tower. Period one was characterised by low wind speeds with a local circulation being the dominant influence on the ground based chemical measurements.

Comparisons between the wind speed values are also shown in Fig. 1. The radar and ECMWF analyses at $1100 \mathrm{~m}$ agree to within $<2 \mathrm{~ms}^{-1}$ apart from the night of the 4th. At the lower levels wind speeds were very variable on $1 \mathrm{st}$ and $2 \mathrm{nd}$, then settled into a sea breeze pattern with minimum speeds in early morning and maxima in late afternoon. The sea breeze circulation was not represented in the ECMWF model which bears little resemblance to the lower- level winds. These comparisons confirm that period one was dominated by local flow introducing a high degree of error to trajectory calculations based on the ECMWF model. Indeed there are occasions in Fig. 1 where the sonic anemometers at $10 \mathrm{~m}$ (red line) and $24 \mathrm{~m}$ (green line) on the tower show wind speeds that differ by up to to $2.0 \mathrm{~ms}^{-1}$, emphasizing that species at different altitudes during this period cannot be assumed to share a common source region.

\subsection{Meteorological period two}

This pattern of sea and land breezes disappeared on the morning of 6 August after the passage of an occluded front. Hence period two was defined between 6 and 11 August. During this period the wind direction was generally westerly to north-westerly, apart from the 8th when the centre of a depression passed just south of Mace Head. During the passage of the depression the wind direction went full circle in an anti-clockwise direction from northwesterly to northerly.

The comparison for period two shows the wind direction measurements for the lower and upper levels tracking each other closely (Fig. 2). Excellent agreement was observed between the measurements and the ECMWF model analysis; 

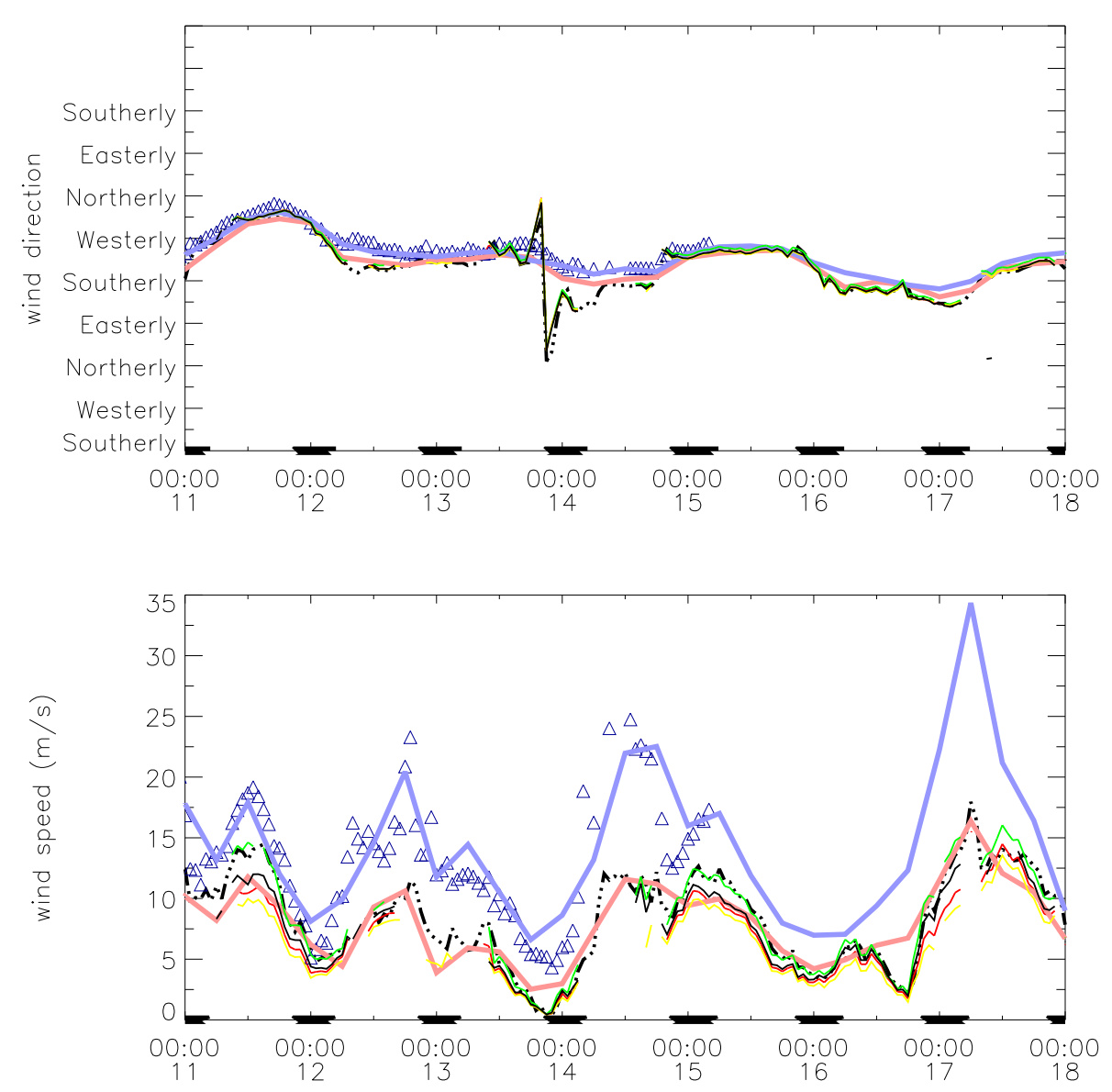

Fig. 3. The same as Fig. 1 but for period three.

a brief exception to this rule occurred on the night of the 10th when the wind speed dropped to $<2 \mathrm{~ms}^{-1}$ and hence local circulation effects dominated. For most of this period the wind speeds at $1100 \mathrm{~m}$ were similar to those near the ground. Interestingly this agreement is not exhibited by the ECMWF analyses, where winds are almost always stronger at the higher level. The model also fails to capture the variability of the measured winds, suggesting that some local influences were present during this period. Nevertheless, the good agreement in wind direction and overall average correctness of the speeds suggests that the ECMWF trajectory calculations should be fairly reliable during this period.

\subsection{Meteorological period three}

Another depression and occluded front passed over Mace Head on the evening of the 10th and early hours of the 11th. After the depression passed, a north-westerly airflow ensued and a ridge of high pressure started to develop, defining period three. During this period three frontal systems passed over Mace Head, with the wind direction retaining a westerly component throughout (Fig. 3). As in period two the measured wind directions at the upper and lower levels were almost identical, with the ECMWF model in close agreement. An exception was observed during the night/morning of the 13th/14th when the lower level wind vector rotated through the west. This was accompanied by very low wind speeds $<2 \mathrm{~ms}^{-1}$. This time however the model and measurements also agree on wind speed (Fig. 3), with both showing winds approximately $5 \mathrm{~ms}^{-1}$ stronger at the upper level than the lower level. We therefore conclude that trajectory calculations should be valid during this period.

\subsection{Meteorological period four}

After the passage of a warm and a cold front on the 17th the wind speed dropped off and anti-cyclonic conditions set in, with the direction remaining generally westerly (Fig. 4). Radar data were only available from the 22nd on and agree very well with the ECMWF model direction. The ECMWF analyses seem to capture a weak representation of the sea breeze from the 18th to 20th, seen in the low level wind direction and speed (Fig. 4). A sea breeze also occurred on the 25th.

The radar data from the 22nd onwards measured almost identical wind directions to the low-level instruments. Sodar 

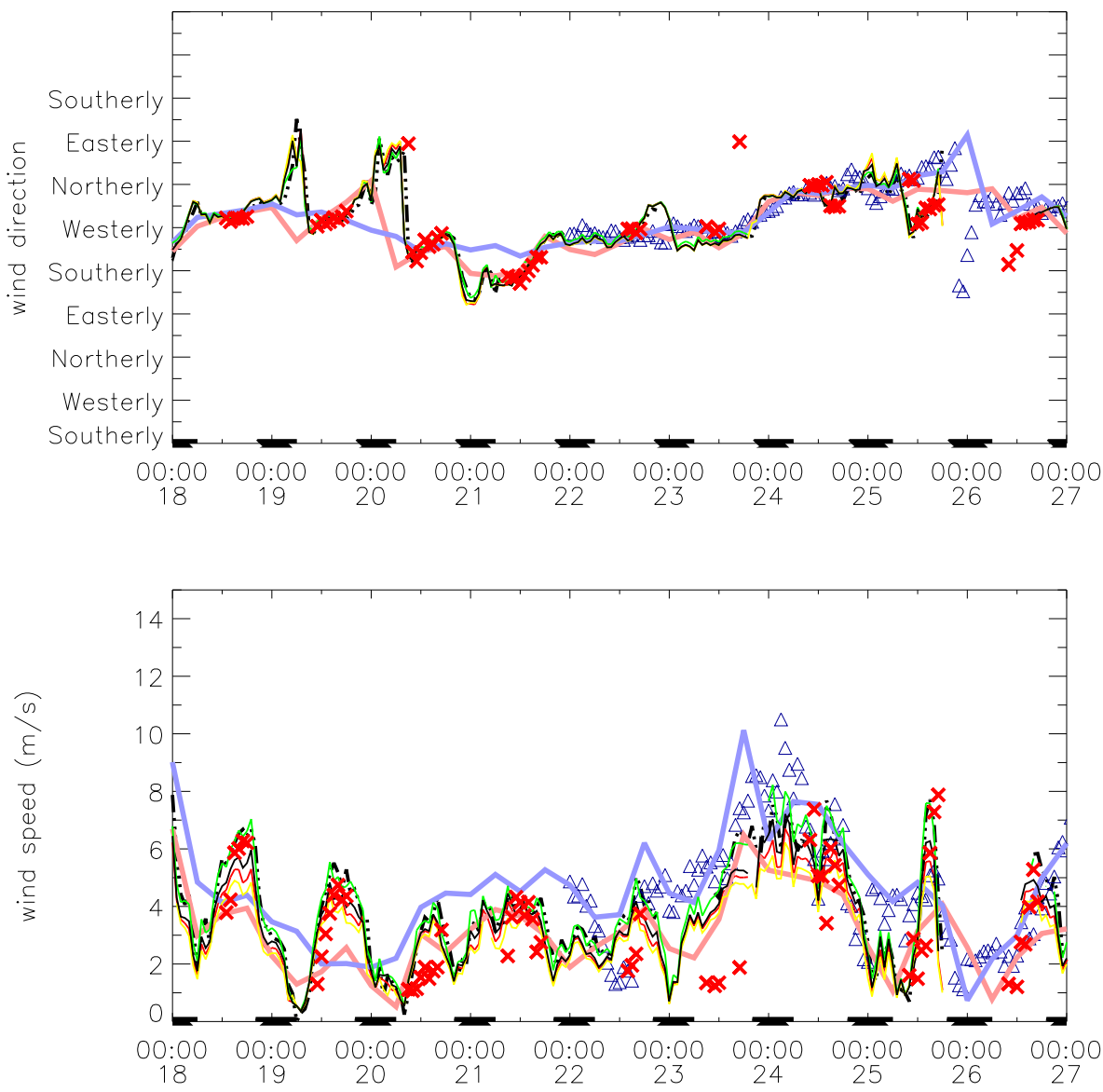

Fig. 4. The same as Fig. 1 but for period four and including sodar data (red crosses).

measurements at $100 \mathrm{~m}$ (red crosses), available only during the day, closely tracked the ECMWF model at $10 \mathrm{~m}$ apart from the 23rd for speed. This was because in low wind conditions $(<5 \mathrm{~m} / \mathrm{s})$ the sodar is more susceptible to the effects of ambient noise. This problem is reduced by using a $2 \mathrm{~m}$ high acoustic shield, unfortunately during this period only a $1 \mathrm{~m}$ hight shield was used. Agreement with the model wind speeds is generally good at both levels apart from the sea breeze events. Trajectory calculations, outside of the sea breeze periods, should be reliable during this period.

\subsection{Meteorological period five}

Radar data ceased on the 30th and the anemometers and sodar data on 1 September as the campaign ended. This westerly period was very similar to period two, with excellent agreement in wind direction between all the measurements and the ECMWF model and little directional wind shear in the boundary layer as shown by Fig. 5 . At both levels the wind speeds showed good agreement as shown by Fig. 5 indicating that trajectory calculations should be reliable during this period.
Table 4. Comparison statistics of the ECMWF model analysis with the wind profiler at $1100 \mathrm{~m}$ (1-15 and 21-31 August) and with the sonic anemometer at $10 \mathrm{~m}$ (6-19, 22-24 and 26-31 August) .

\begin{tabular}{cccc}
\hline Altitude & \multicolumn{3}{c}{$1100 \mathrm{~m}$} \\
Parameter & speed & $\mathrm{u}$ & $\mathrm{v}$ \\
\hline Correlation Coefficient $^{-0.9228}$ & 0.9680 & 0.9302 \\
RMS (ms $^{-1}$ ) & 1.8148 & 1.5176 & 2.1470 \\
Slope & 1.0272 & 0.9680 & 1.0176 \\
Error in Slope $(1 \sigma)$ & 0.0228 & 0.0268 & 0.0438 \\
\hline Altitude & & $10 \mathrm{~m}$ & \\
Parameter & speed & $\mathrm{u}$ & $\mathrm{v}$ \\
\hline Correlation Coefficient & 0.8585 & 0.8937 & 0.9424 \\
RMS (ms & \\
Slope & 1.5210 & 1.3822 & 1.4558 \\
Error in Slope $(1 \sigma)$ & 1.0607 & 0.9506 & 0.9042 \\
& 0.0411 & 0.0736 & 0.0495
\end{tabular}



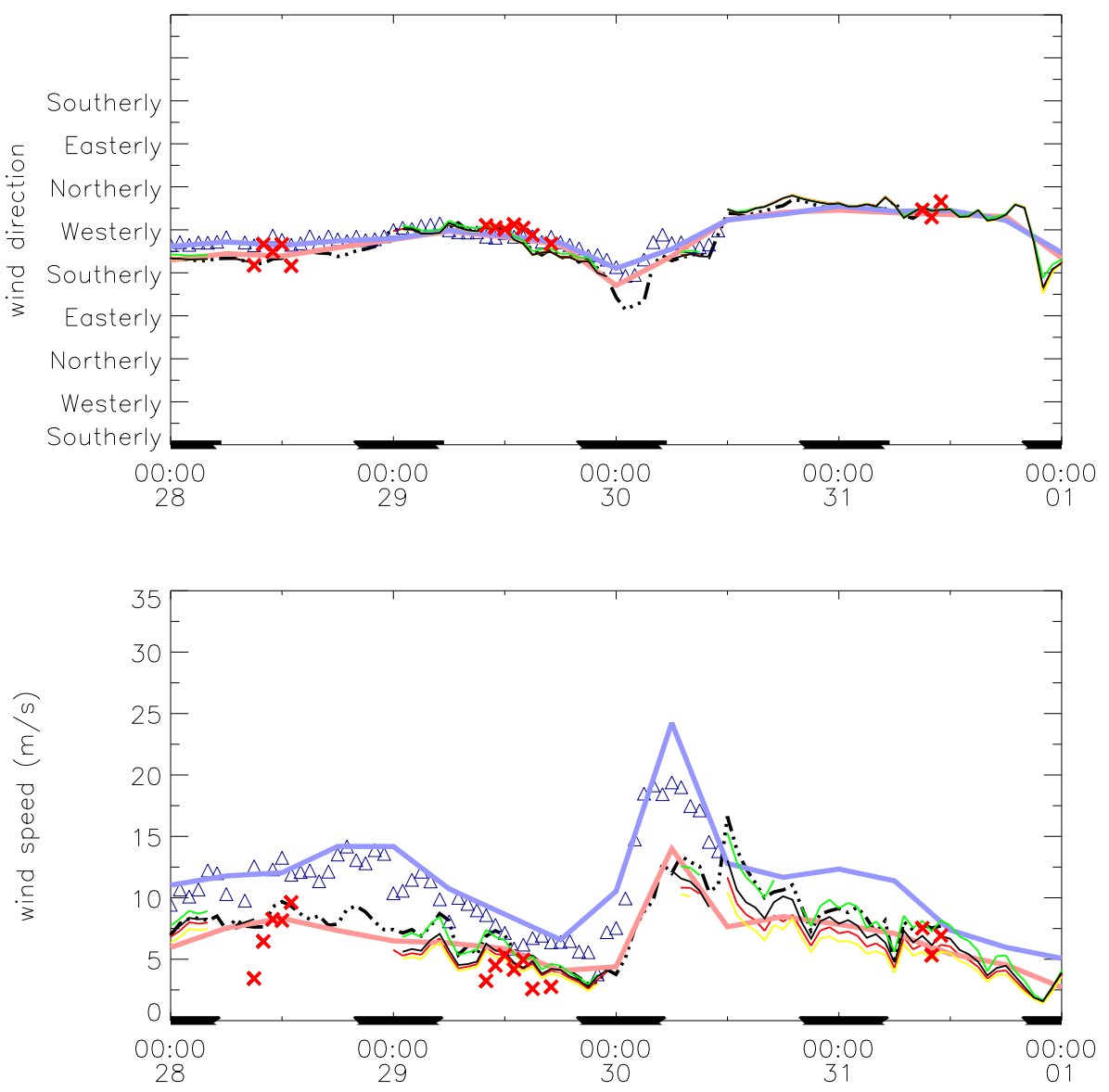

Fig. 5. The same as Fig. 4 but for period five.

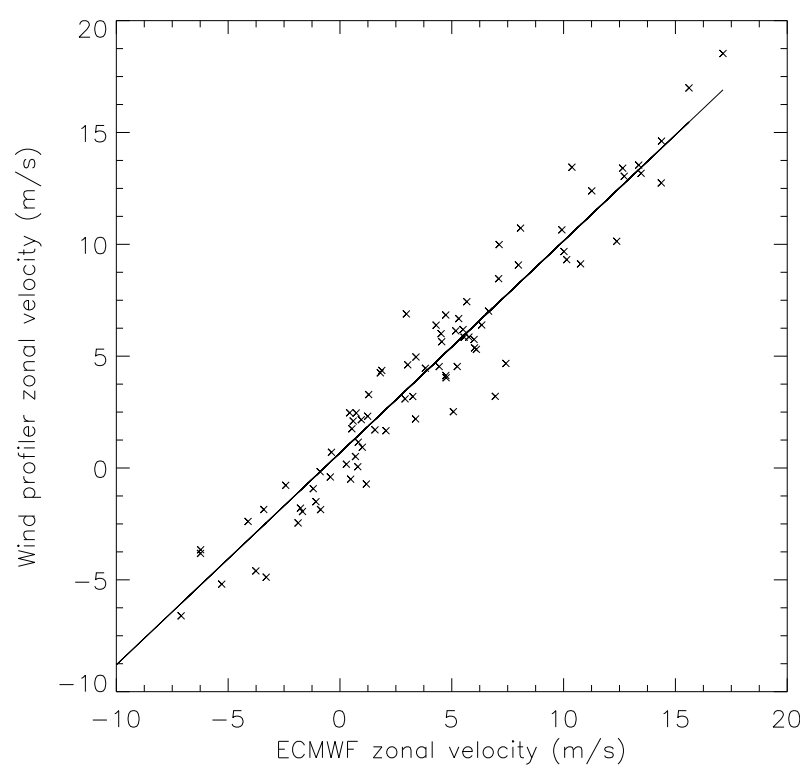

Fig. 6. Comparison of wind profiler and ECMWF zonal velocity of wind at $1100 \mathrm{~m}$ during NAMBLEX.

\subsection{Comparison statistics}

In summary, during the majority of the campaign good agreement was observed between the meteorological measurements and the ECMWF model analysis. The major discrepancies were found at the lower altitudes during the sea breeze events that occurred in period one and also between 17 and 22 August and 25 August. Hence outside the sea breeze events trajectory calculations based on ECMWF model analysis should be reliable. Comparison statistics between the ECMWF model and the wind profiler data were calculated for the whole measurement period at $1100 \mathrm{~m}$. Comparisons with the sonic anemometer at $10 \mathrm{~m}$ has only been made during periods when sea breeze events were absent. The values of the correlation coefficients ( $r$ ), root mean squared residual (RMS), slope and slope error at $1100 \mathrm{~m}$ and $10 \mathrm{~m}$ are given for the wind speed, zonal velocity (u) and meridional velocity (v) in Table 4. Correlation coefficients at the upper level gave an average value of $r=0.940$ and at the lower level an average value of $r=0.898$ confirming that outside the sea breeze events at the lower altitudes the ECMWF six hour model analysis of wind speed and direction were reliable. The slopes are within $2 \sigma$ of 1.00 in all cases, and are mostly 

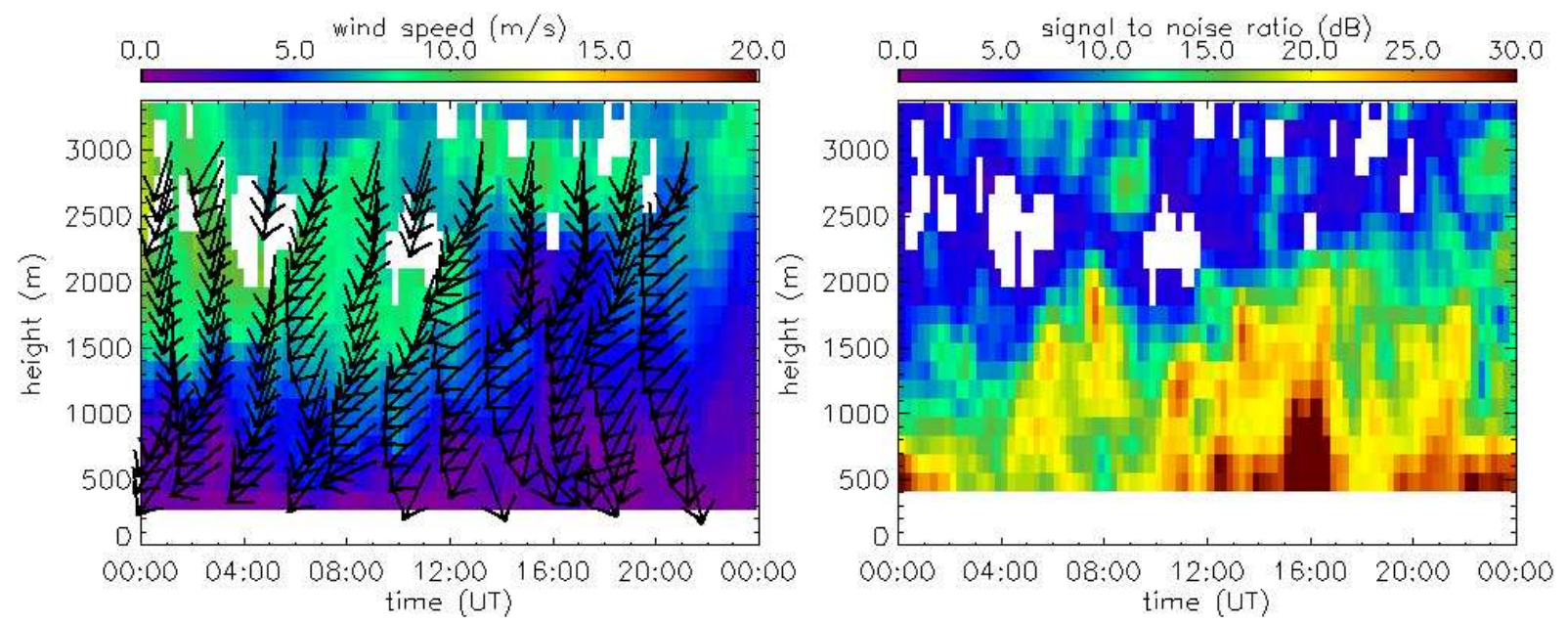

Fig. 7. $1290 \mathrm{MHz}$ wind profiler data for the 4 August 2002 (a) Wind speed and direction (b) Minimum signal to noise ratio.

within $1 \sigma$, showing that there is no detectable systematic offset between the model analyses and the measurements at either level outside of the sea breeze periods. Figure 6 shows an example of a scatter plot for the zonal component of wind for the wind profiler throughout the duration of the campaign.

\section{Planetary boundary layer structure}

The Planetary boundary layer (PBL) is defined as the lowest part of the atmosphere directly influenced by the Earth's surface on a time period of 1 day or less (Stull, 1988). The depth of this layer is dependent on surface heating by the Sun leading to convection. Over land under high pressure conditions there is usually a daily cycle of the planetary boundary layer, growing during the day and collapsing at night as the Earth's surface cools and mixing is suppressed. During the night (or over the ocean) a stable boundary layer often forms. Coupling between the PBL and the surface has an impact on understanding ground-based chemical measurements made during NAMBLEX. This section gives a brief overview of the PBL structure during NAMBLEX. The structure of the PBL at the coastal environment of Mace Head was observed by lidar during PARFORCE to vary from a single well mixed layer to multilayered structures (Kunz, 2002). The UHF radar observations during NAMBLEX showed that the PBL was more complex than at an inland location hence full details of the PBL structure during NAMBLEX will be given in a later paper.

Two properties of the atmosphere give rise to UHF radar echoes: turbulence and vertical gradient in refractive index. Where they occur together as in a convective plume strong echoes results, so that the radar can readily identify the convectively mixed boundary layer. In the lower atmosphere refractive index gradients are caused mainly by humidity gradients, so the radar can identify the hydrolapse typically found at the top of the boundary layer, as well as internal residual layers (Angevine et al., 1994; Angevine et al., 1998; Grimsdell and Angevine, 1998).

On sea breeze days such as 4 August a stable boundary layer with shear-driven turbulence was observed. On this day the prevailing wind was north-easterly (Fig. 7). The reflectivity profiles show that in this case there is no obvious diurnal evolution of a mixed layer. Enhanced signals are sometimes observed up to altitudes as high as $2000 \mathrm{~m}$ but it is not clear where to assign the depth of the boundary layer. The enhanced reflectivity at 16:00 was due to Rayleigh scattering from precipitation.

The only definite example of a convectively-mixed layer was on 9 August (Fig. 8). On this day light northerly (i.e. offshore) winds prevailed. The radar reflectivity shows the growth of a layer of high echo power between 08:00 and 10:00, with its upper edge around $1 \mathrm{~km}$ up to $17: 00$, after which the layer gradually subsides. Note however the existence of layers of elevated reflectivity in the night-time boundary layer and at $2 \mathrm{~km}$ during day. We interpret the former as residual layers, and the latter as the boundary-layer top, presumably resulting from stronger convection further inland over the hills to the north of Mace Head. The clockwise turning of the wind with height within the lowest $500 \mathrm{~m}$ is clear on this day, particularly during the convective period.

Although the 9 August and other days of offshore winds such as the 2nd, 24th and 25th showed some evidence of a mixed layer, this was not typical of the measurements made at Mace Head. A more typical representation of the PBL is shown in Fig. 9 for the 11 August when the winds were light westerly to northwesterly (i.e. onshore). A maximum in reflectivity was observed to vary between $600 \mathrm{~m}$ and $1500 \mathrm{~m}$ throughout the whole day. Some convective plumes were evident but no obvious diurnal cycle. It is likely therefore that the mixed layer (if it existed) was too shallow to be observed by the radar. 

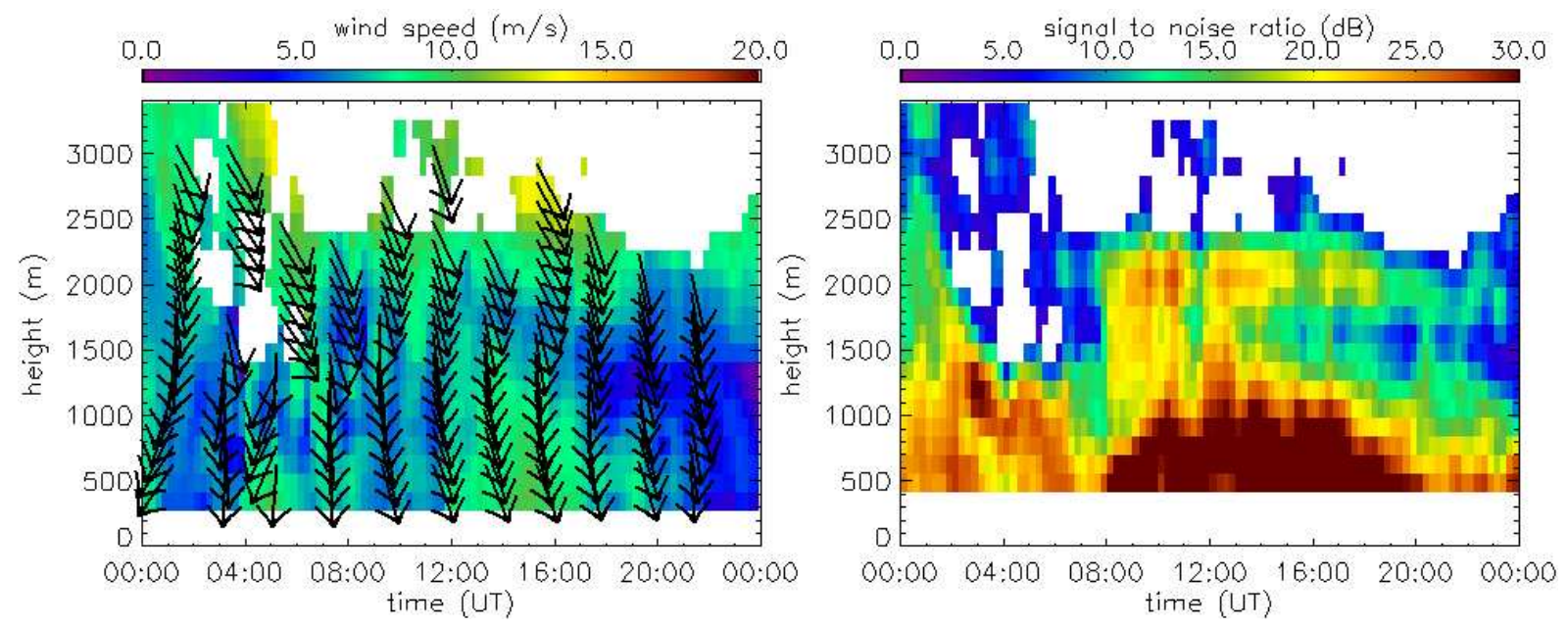

Fig. 8. The same as Fig. 7 but for the 9 August 2002. Note the clockwise turning of the wind direction with height within the turbulent boundary layer is extremely clear in this picture.

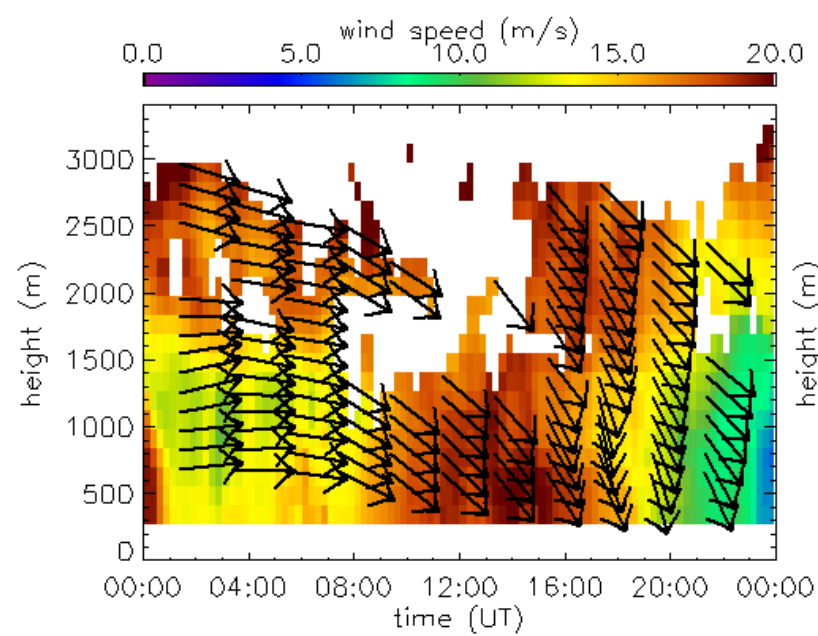

Fig. 9. The same as Fig. 7 but for the 11 August 2002.

Updrafts during large scale weather features such as the passage of the occluded front on the afternoon of the $10 \mathrm{Au}$ gust obliterated any surface effects as shown in Fig. 10. PBL air is transported high into the atmosphere hence strong reflectivity signals are observed to $>3000 \mathrm{~m}$. During the strong winds between 17:00 and 23:00 $\mathrm{h}$ the enhanced SNR was associated with precipitation. During the passage of this weak forward-sloping (kata) front the wind speeds were observed to increase very suddenly by approximately $10 \mathrm{~ms}^{-1}$. There was no significant change in wind direction associated with the front shown in Fig. 10. The change in wind direction preceding the front was associated with a ridge of high pressure passing over the site.

To summarise, the idealised convective land based diurnal cycle of the PBL was only observed on a few days. The more typical PBL during the NAMBLEX campaign was one that was more oceanic in nature showing much less diurnal variation and less evidence for strong vertical mixing.

\section{Surface layer turbulence structure}

The development of an internal boundary layer at a surface roughness boundary has been widely studied in the past (Stull, 1998, and references therein). At the transition from an ocean surface to land, the advecting air experiences increased drag as a result of increasing surface roughness. However, the surface layer takes some time to fully respond to the change in surface conditions. The air next to the surface experiences an instantaneous reduction in mean speed but the air aloft will not respond immediately. Rather the reduction in wind speed with height propagates vertically at a rate governed by its response to the drag it experiences 

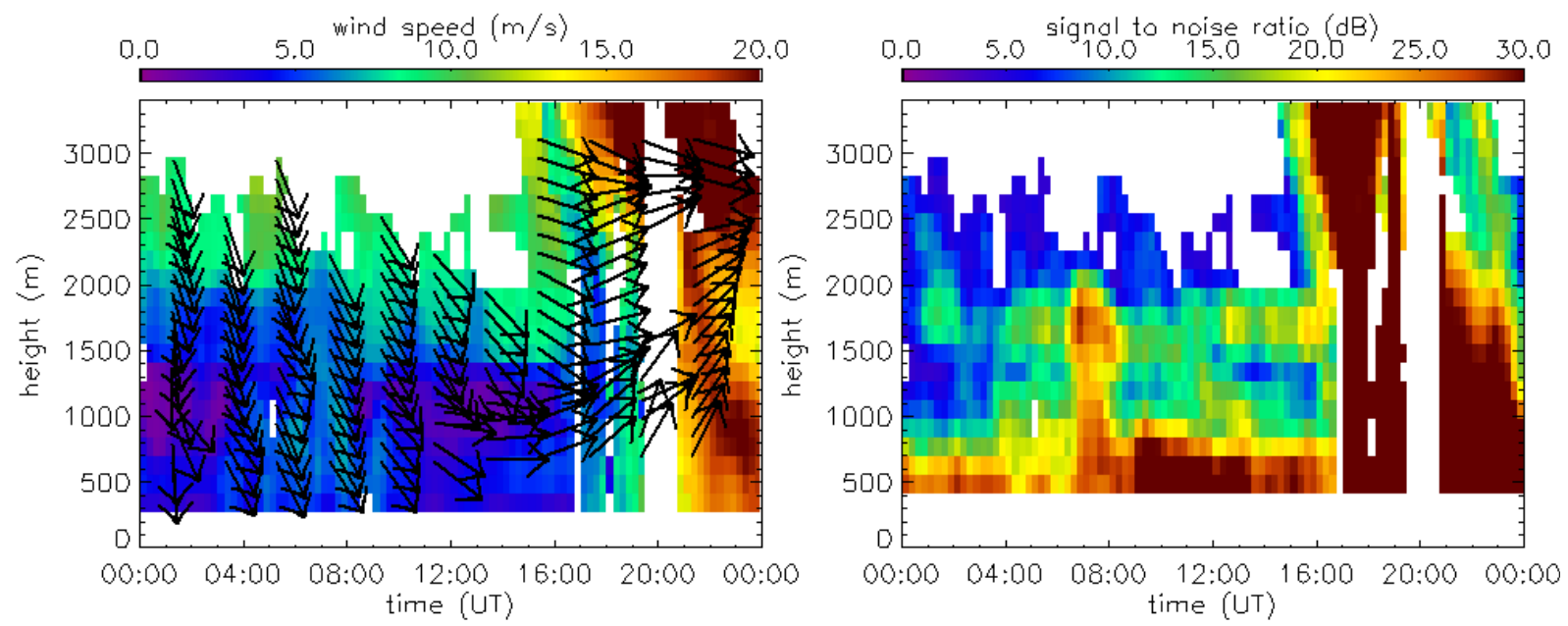

Fig. 10. The same as Fig. 7 but for the 10 August 2002.

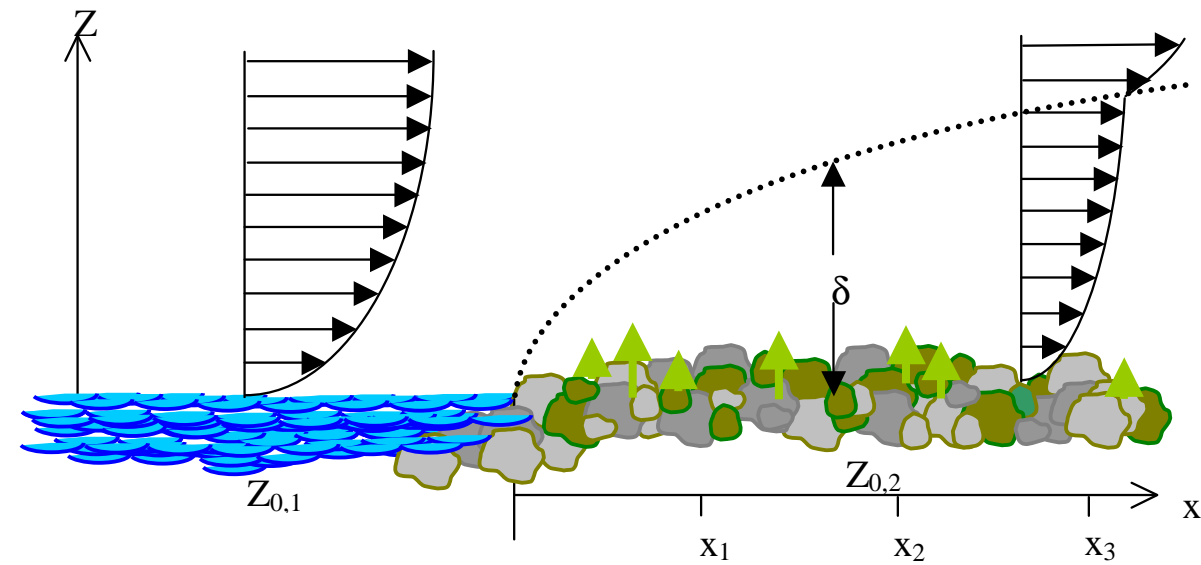

Fig. 11. Schematic of the development of an internal boundary layer arising from a change in surface roughness at the shoreline.

from the immediately underlying air. Wave breaking on the shoreline will produce large sea salt particles (Kunz, 2002) and this production is likely to be significantly influenced by the developing internal boundary layer and will be retained within it. The inter-tidal zone at Mace Head has previously been shown to be a source of iodocarbons (Carpenter, 2003) and these species have been linked with ultrafine particle formation (O'Dowd et al., 2002; McFiggans et al., 1998). The developing internal boundary layer will act to restrict the vertical diffusion of such emissions. It was therefore important to understand the micrometeorology of the internal boundary layer in a range of stability conditions, wind directions and tidal heights during NAMBLEX to establish whether the sample inlets were likely to be within the internal boundary layer and therefore whether they may be impacted by any gas or particle sources in the inter-tidal zone.

Turbulence statistics were calculated from the sonic data every $15 \mathrm{~min}$ throughout the experiment Fig. 12. The stress is measured by the covariance of the horizontal and vertical winds and is a measure of the in-situ momentum flux at any given height. Figure 12a shows the normalised average stress as a function of height above sea level in three different onshore wind sectors. There is clearly no perturbation to the stress profile in either the southerly or south-westerly wind sectors at the $15 \mathrm{~m}$ level or above but the $10 \mathrm{~m}$ level shows an increase in stress, indicating that the internal boundary layer development has reached between 10 and $15 \mathrm{~m}$ at the sampling location. In the north-westerly sector there is some indication that the stress at $15 \mathrm{~m}$ has been perturbed, though the effect is considerably smaller than at the levels below. This enhancement may be due to a much steeper coastal bluff in that direction but may also be caused by some interference from the main laboratory, which was $8 \mathrm{~m}$ high and was located immediately upwind of the tower in this wind direction. These data show the internal boundary layer height is at or below $15 \mathrm{~m}$ in all of the sampled marine air masses during the experiment. Figure $12 \mathrm{~b}$ shows the impact of tidal height on the shape of the stress profile. There is some indication that 

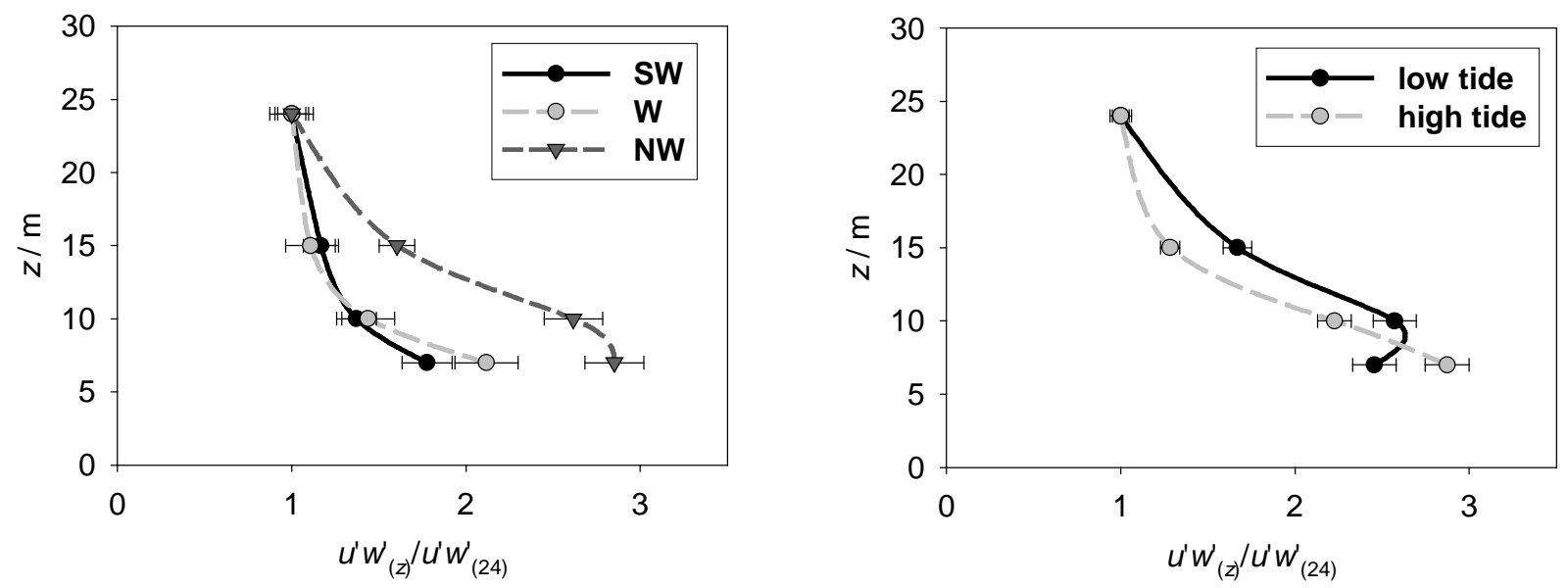

Fig. 12. Normalised stress profile, averaged over the entire experimental period as a function of (a) wind direction degrees and (b) tidal height.

the stress perturbation is larger at low tide due to the greater exposure of the inter-tidal coast, however, there is no indication that the perturbation affects the wind profile at $24 \mathrm{~m}$, demonstrating that in all wind directions and tidal conditions the measurements made from the $24 \mathrm{~m}$ are free from the immediate influence of the shore. It is likely that measurements made at, or below 10-12 m, will be significantly impacted by shoreline or inter-tidal emissions. Previous work (Carpenter, 2003) has provided evidence for iodocarbon profiles that support these findings. It is recommended that the discontinuities in the surface profile arising from changes in surface roughness be considered when interpreting data at Mace Head that is likely to have significant coastal sources.

\section{Conclusions}

This paper has presented a meteorological overview of the NAMBLEX field campaign, for use in interpreting the chemical measurements. The comparative investigations found that on the whole the ECMWF model analysis at $10 \mathrm{~m}$ and $1100 \mathrm{~m}$ agreed well with the meteorological measurements, but on a number of days the local winds were very different to the synoptic flow. The greatest discrepancies were observed between the 1 and 6 August when the winds were light and sea breeze effects dominated. Sea breezes were also observed between 17 and 22 August and on the 25th. On days when the local flow was different from the synoptic, trajectory calculations based on the ECMWF model should be treated with caution. The UHF radar reflectivity profile have also been used to identify days when the boundary layer could be considered convectively mixed up to $\sim 1 \mathrm{~km}$. In fact such days were rare: when on-shore winds prevailed the boundary layer showed little evidence of active mixing above $\sim 700 \mathrm{~m}$. Turbulence statistics have been used to assess the development of the internal boundary produced by the change in roughness at the shoreline at the measurements location.

Stress profiles show that in all marine sectors sampled the stress profile is perturbed, indicating the influence of the internal boundary layer, at the $10 \mathrm{~m}$ sample level and below. There is some evidence that this may reach $15 \mathrm{~m}$ in the north westerly sector, though the terrain and the laboratory may induce artifacts under these conditions. The increased intertidal fetch at low tide is measurable in the stress profile but does not show that the internal boundary layer propagates to $24 \mathrm{~m}$, even at low tide. However, sampling at, or below, $15 \mathrm{~m}$ may be affected under low tide conditions.

Acknowledgements. The authors would like to thank D. Heard and all their colleagues involved in NAMBLEX. Credit is also due to P. Currier and colleagues at Degreane for their help with the wind profiler. This work was supported by University Facility for Atmospheric Measurements (UFAM) and British Atmospheric Data Centre (BADC).

Edited by: D. Heard

\section{References}

Angevine, W. M., White, A. B., and Avery, S. K.: Boundary layer depth and entrainment zone characteriztion with a boundary layer profiler, Bound.-Layer Meteor., 68, 375-385, 1994.

Angevine, W. M., Grimsdell, A. W., Warnock, J. M., Clark, W. L., and Delany, A. C.: Flatland boundary layer experiments, Bull. Amer. Meteor. Soc., 79, 419-431, 1998.

Carpenter, L. J., Liss, P. S., and Penkett, S. A.: Marine organohalogens in the atmosphere over the Atlantic and Southern Oceans, J. Geophys. Res., 108(D9), 4256, doi:10.1029/2002JD002769, 2003.

Doviak, R. J. and Zrnic, D. S.: Doppler Radar and Weather Observations, Academic Press, 1993. 
Grimsdell, A. W. and Angevine, W. A.: Convective boundary laer height measuremnts with wind profilers and comparison to cloud base, J. Atmos. and Oceanic. Tech., 15(6), 1331-1338, 1998.

Heard, D., Read, K., Methven, J., et al.: The North Atlantic Marine Boundary Layer Experiment (NAMBLEX). Overview of the campaign held at Mace Head, Ireland, in summer 2002, Atmos. Chem. Phys. Discuss., 5, 12 177-12 254, 2005,

SRef-ID: 1680-7375/acpd/2005-5-12177.

Kunz, G. J., de Leeuw, G., Becker, E., and O'Dowd, C. D.: Lidar observations of atmospheric boundary layer structure and sea spray aerosol plumes generation and transport at Mace Head, Ireland (PARFORCE experiment), J. Geophys. Res., 107(D19), 8106, doi:10.1029/2001JD001240, 2002.
McFiggans, G., Coe, H., Burgess, R., Allan, J., Cubison, M., Alfarra, M. R., Saunders, R., Saiz-Lopez, A., Plane, J. M. C., Wevill, D. J., Carpenter, L. J., Rickard, A. R., and Monks, P. S.: Direct evidence for coastal iodine particles from Laminaria macroalgae - linkage to emissions of molecular iodine, Atmos. Chem. Phys., 4, 701-713, 2004,

\section{SRef-ID: 1680-7324/acp/2004-4-701.}

O’Dowd, C. D., Jimenez, J. L., Bahreini, R., Flagan, R. C., Seinfeld, J. H., Hameri, K., Pirjola, L., Kulmala, M., Jennings, S. G., and Hoffmann, T.: Marine aerosol formation from biogenic iodine emissions Nature, 417(6889), 632-636, 2002.

Stull, R. B.: An introduction to boundary layer meteorology, Kluwer Academic Publishers, London, 1988. 